\title{
Cultura e desenvolvimento humano: saberes divulgados em um impresso brasileiro do século $X I X$
}

\section{Culture and human development: knowledge published in 19th century Brazilian printing}

\section{Raquel Martins de Assis}

Universidade Federal de Minas Gerais - UFMG, Belo Horizonte, Minas Gerais, Brasil

\section{Juliana de Souza Martins}

Universidade Federal de Minas Gerais - UFMG, Belo Horizonte, Minas Gerais, Brasil

\begin{abstract}
RESUMO
Este artigo descreve resultados de pesquisa sobre as relações entre cultivo das faculdades da alma e educação na cultura impressa do século XIX, no Brasil, mais especificamente em Minas Gerais. Trata-se de um estudo em história da psicologia da educação com o objetivo de investigar as relações entre concepções sobre desenvolvimento humano, faculdades intelectuais e morais e discurso educativo presentes na cultura impressa. O texto apresenta a análise da Secção Scientífica ou Pedagogia, redigida por José Miguel de Siqueira e publicada no jornal O Baependyano (1877-1889). Na Secção, a pedagogia, vista como moderna, é definida como alargamento e expansão das forças da alma humana, evidenciando relações entre desenvolvimento humano e educação. O desenvolvimento, por sua vez, é dirigido por formas específicas de cultura. Para a conceituação de educação, bem como de cultura, Siqueira apropria-se de ideias francesas divulgadas na época, assim como de tradições já bem solidificadas na província, como os ideais católicos.
\end{abstract}

Palavras-chave: história da psicologia, século XIX, faculdades da alma, cultura, desenvolvimento humano.

\begin{abstract}
The present article describes the results of a research on the fostering of the faculties of the soul and education in the $19^{\text {th }}$ century printed culture, in Brazil, more specifically in the State of Minas Gerais. It is a study within the psychology of education aiming to investigate the relationship among human development concepts, intellectual and moral faculties and educating discourse published in a journal. The text brings the analysis of the Secção Scientífica (Scientific Section) also named Pedagogy, written by José Miguel de Siqueira and published in the journal "O Baependyano" (1877-1889). In this Section, modern pedagogy is defined as the broadening and expansion of the forces of the human soul. The development, itself, is determined by innate aspects and conveyed by specific cultural forms. For the conceptualization of education, as well as culture, Siqueira takes the French ideas divulged at that time, in addition to traditions already quite settled in the region, such as the catholic ideas.
\end{abstract}

Keywords: psychology history, $19^{\text {th }}$ century, faculties of the soul, culture, human development. 


\section{I ntrodução}

O presente artigo tem o objetivo de apresentar parte dos resultados de uma pesquisa cujo objetivo foi investigar o tema das faculdades da alma e de suas implicações para a educação na cultura impressa brasileira do século XIX. Este estudo apresenta a análise da Sceção Scientífica ou Pedagogia, redigida por José Miguel de Siqueira e publicada no O Baependyano, jornal surgido em julho de 1877, na cidade de Baependi, localizada no sul de Minas Gerais - Brasil, e que circulou por esta cidade até novembro de 1889. Dos resultados da investigação realizada na Secção Scientífica emergiu o interesse pelo tema da cultura das faculdades da alma e sua relação com o desenvolvimento humano como objeto para a história da psicologia da educação, chamando a atenção para a importância dos jornais não propriamente científicos como instrumentos importantes para a divulgação de saberes relacionados à psicologia no século XIX.

De modo geral, desde o século XVIII havia, no espírito da época, uma crescente valorização do papel dos periódicos como instrumentos educativos (PALLARES-BURKE, 1995; LUSTOSA, 2003,2008; ARAÚj O, 2008) bem como uma forte crença na educação e na formação dos costumes como recursos para o desenvolvimento do homem civil e religioso (MENDES et al., 2008). Como afirma Lustosa (2008, p. 12), "os jornais eram a voz pública de seus redatores e tinham por finalidade divulgar suas idéias". Tal voz, por sua vez, tornava-se forte, devido à importância que os homens da época davam ao papel da imprensa como forma de educação dos povos e como substituta natural da escola e do livro (LUSTOSA, 2008).

No Brasil do século XIX, os periódicos adquiriram um significado singular devido à liberação, dada pela Coroa portuguesa, para a abertura de tipografias e para edição e publicação de livros diversos, jornais e periódicos variados e compêndios para o ensino.

Assim, nesse período, houve efervescente produção e circulação de cultura impressa cujos objetivos eram promover a educação e a formação dos costumes por meio da leitura. Em Minas Gerais, na metade do século XIX, um forte movimento foi liderado por Dom Antônio Viçoso, bispo de Mariana, e seu grupo de clérigos e de leigos. Eles trabalharam na tradução, publicação e divulgação de diversas obras e textos impressos que circularam na Província. Essas obras e impressos tinham a finalidade de educar os costumes da população local e de afirmar o catolicismo, lutando contra algumas teorias iluministas e tradições vistas como "anticatólicas", tais como o deísmo e o materialismo, anunciadas em terras mineiras (RODRIGUES, 1986; ASSIS, 2004). Neste debate entre teorias materialistas e tradição religiosa, aparece, de forma recorrente, a ideia de que a pessoa e a sociedade possuem a mesma estrutura, sendo a primeira entendida como microcosmo e a segunda como 
macrocosmo. Estabeleciam-se relações entre os conceitos de pessoa moral e de corpo social, definindo-os como uma inteligência servida por órgãos (corpo), sendo os homens os órgãos da sociedade e as leis a sua inteligência. Diante disso, tornava-se necessário o cuidado com a educação e com o adequado desenvolvimento das faculdades da alma, entre elas a inteligência, principalmente das crianças e da mocidade.

Nesse contexto, saberes sobre psicologia ganharam relevo, pois resultados de pesquisas envolvendo a cultura impressa do século XIX, no Brasil, mostraram que, na época, a psicologia encontrava-se associada aos temas das faculdades da alma humana, das origens da ideia e da relação mente-corpo (ASSIS, 2009b). Cabia à psicologia estudar tais fenômenos, enquanto a educação teria o objetivo de dirigir as faculdades da alma a fim de formar o ser humano civilizado, moral e polido. Assim, na época, se fazia evidente a relação, entendida como cultura, entre práticas educativas e desenvolvimento das faculdades da alma, como demonstra o trecho de um manuscrito encontrado no Arquivo Episcopal da Arquidiocese de Diamantina e escrito por um autor anônimo do século XIX:

Contava então 16 para 17 annos de idade, proximo do limite entre a infancia e a puberdade, tempo em que as faculdades intellectuaes saen desabrochar com certo vigor ascendente, e promettendo fructos copiosos, uma vez que sejam bem cultivadas e bem dirigidas. (manuscrito Biografia de Dom J oão Antônio dos Santos, sem data, p. 14)

Nesse texto, o autor caracteriza a época entre a infância e a puberdade como o tempo em que as faculdades intelectuais se desenvolvem com "vigor ascendente", ou seja, o fim da infância seria o período de maior desenvolvimento das faculdades intelectuais, daí o cuidado com as práticas educativas nessa época. Nesse sentido, para que o desenvolvimento se dê de forma eficaz é preciso que elas sejam cultivadas e dirigidas adequadamente.

Buscando discutir as relações entre a teoria das faculdades da alma, entendida como a parte psicológica da filosofia, a educação, conceituada como um conjunto de práticas que dirigem e que possibilitam o desenvolvimento dessas faculdades, e a cultura, esse artigo apresenta aspectos da análise dos textos sobre Educação Moral, Educação e Instrução e Educação Estética publicados na Secção Scientífica ou Pedagogia do jornal O Baependyano, entre 1879 e 1881. Nesses escritos, Siqueira apresenta sua definição de pedagogia moderna, discutindo os temas da formação do ser humano e da cultura das faculdades da alma.

Em termos metodológicos, a análise obedeceu ao seguinte procedimento: 1) foi realizada a leitura de todos os textos denominados Secção Scientífica e Pedagogia no período acima citado. 
Essa seção tratava de temas ligados à educação, mas alternava seus títulos entre Secção Scientífica e Pedagogia, não sendo possível faze uma distinção entre os textos denominados científicos e aqueles intitulados como pedagógicos; 2) a partir dessa amostra maior, foram escolhidos os textos que apresentavam o tema da cultura, fazendo um levantamento dos trechos expressivos sobre as relações entre desenvolvimento humano, faculdades da alma e educação e organizando-os em categorias; por fim, foi realizada a descrição dessas categorias e sua análise, bem como a investigação das apropriações presentes.

O artigo aqui proposto expõe parte desses resultados e se organizará da seguinte forma: apresentaremos brevemente 0 jornal 0 Baependyano e a Seção redigida por José Miguel de Siqueira. Em seguida, descreveremos o conceito de cultura apresentado pelo jornal e sua relação com o desenvolvimento humano e com a definição de pedagogia encontrada no periódico.

\section{A Secção Scientífica ou Pedagogia publicada no jornal 0 Baependyano.}

A cultura impressa do século XIX têm especificidades próprias de sua época, sendo marcante uma relação muito estreita entre jornais e compêndios, pois geralmente os periódicos eram formados em grande parte pelos fragmentos de compêndios e de outros gêneros literários da época e comumente eram compilados em forma de livro, quase se tornando um manual (PALLARES-BURKE, 1995). Devido a essa característica, a leitura de jornais nos permite perceber que autores eram lidos, de que maneira estavam sendo usados e também com que finalidade diferentes grupos sociais se utilizavam deste ou daquele autor, bem como dos livros da época, nos fazendo conhecer assim as tensões e os diálogos travados entre os intelectuais da época, bem como os debates entre posições teóricas diversas. De certa forma, o periódico devido a sua forma de se organizar como escrita cujo objetivo é informar e educar, nos permite vislumbrar algo do cotidiano e das maneiras como os compêndios e suas teorias eram apropriados pelas pessoas da época.

No Baependyano, como era comum nesse tempo, é possível encontrar apropriações de compêndios, obras e autores diversos. Assim, a Secção é marcada pela presença de diversas tópicas como: o conceito de homem terrestre próprio da tradição cristã, a oposição virtude/vício elaborada a partir de Friedrich Froebel, citações do Emílio de Jean Jacques Rousseau, ideias educacionais de Johann Heinrich Pestalozzi, o tema da cultura e das diferenças entre as pessoas discutidas a partir das Cartas do Papa Clemente XIV, dentre outras. Uma obra de presença marcante nos textos é o manual 
pedagógico intitulado Curso theorico e pratico de Pedagogia (1862/1885) escrito por Michel Charbonneau, de grande circulação em Minas Gerais, de onde Siqueira retira seu conceito de educação definido como cultura e instrução.

O Baependyano se intitulava uma folha scientífica, literária e noticiosa que, por isso, era composto por sessões sobre literatura, ciências, pedagogia, religião e trabalhos rurais. Cada exemplar do jornal era organizado em quatro páginas, sendo a última destinada a fazer propaganda de serviços prestados na cidade e anunciar a venda e a fuga de escravos, como tradicionalmente se fazia no século XIX.

A Seção ora denominada Scientífica e ora intitulada Pedagogia tinha como temática a educação, a instrução e a formação moral. José Miguel de Siqueira, tratava a educação como instrumento privilegiado para a formação do homem social, ou seja, o ideal de ser humano instruído, polido, civilizado e dotado de boas maneiras sociais. Tal ideário insere-se no espírito da época, em que textos como "Professores, civilização e educação", publicado no jornal A Província de Minas (1889), apareciam frequentemente na imprensa periódica.

Não foi possível encontrar muitas informações sobre José Miguel de Siqueira. Dados levantados indicam que ele foi deputado provincial no ano de 1877, autor do livro Educação religiosa (1883) e lavrador e fazendeiro da região de Barbacena - MG. Siqueira parece ter sido um dos colaboradores do jornal O Baependyano, organizado por Amaro Carlos Nogueira, homem de grande influência no cenário político mineiro, membro do Partido Liberal, deputado provincial, jornalista e dono de escola. O Baependyano, segundo Castilho (2009), representava um grupo definido de lavradores e fazendeiros da província contrários ao abolicionismo, mas que defendiam uma lenta emancipação dos escravos a serem substituídos pela mão-de-obra imigrante.

Diante disso, os temas do periódico giram, em grande parte, em torno do trabalho e de sua valorização como aspecto que engrandece a pessoa e a nação, deixando de ser visto como ação inferior destinada ao escravo (Castilho, 2009). O editorial do jornal declarava sua missão de "doutrinar o povo sobre o que lhe importa saber" (05 de setembro de 1880 p.1.) e vangloriava-se por ser "um dos principais diretores de opinião na parte mais adiantada do império" (05 de setembro de 1880 p.1). Entre as questões que, segundo o periódico, interessavam ao povo estavam as ideias sobre o trabalho, sua dignidade e seu valor para a modernidade (CASTILHO, 2009), bem como a educação.

A Seção, redigida por Siqueira, era dividida em cinco grandes temas: Educação Moral, Educação Social, Educação Estética, Educação Doméstica e Social e Educação Física. Nestas subseções, o autor descreve a importância da boa educação (principalmente no que diz respeito à leitura e à escolha dos livros) e da polidez para o 
desenvolvimento de virtudes sociais importantes ao desenvolvimento da nação; conceitua a educação como instrução e cultura; aborda os deveres entre os pais e os filhos e a importância do casamento, da maternidade e da educação social e cristã; trata da faculdade da imaginação e da necessidade de instruir os homens, não somente pela razão, mas também através da beleza das artes e por fim, discute a importância da educação do corpo para a conservação do espírito. Como podemos observar, tais temas eram entendidos como científicos, como por exemplo, as faculdades da alma, daí que a Seção se apresentasse como científica, mas também como pedagógica já que explorava a discussão sobre a educação, nos parecendo impossível separar a parte científica da parte pedagógica. Assim, Siqueira insere-se no contexto do século XIX, no qual se faz fortemente presente um movimento em direção á modernidade que coloca a importância da pedagogia estar fundamentada em preceitos científicos, embora no caso do Baependyano a palavra científica ainda esteja muito ligada à filosofia e não à ciência experimental como já era comum em outras correntes teóricas.

Apesar da diversidade de assuntos presentes no periódico, este artigo tem o objetivo de discutir o tema da cultura das faculdades da alma e sua relação com a educação, assunto recorrente nos artigos intitulados Educação Moral, A Educação e a Instrução e Educação Estética, como veremos a seguir.

\section{A moderna pedagogia e o desenvolvimento humano}

Apregoando a posição de modernidade do jornal O Baependyano, José Miguel de Siqueira define a pedagogia como "o alargamento, a expansão e o desenvolvimento das forças animais, racionais e morais do homem, acompanhado pela instrução entendida como um acessório indispensável à educação e conceituada como a obtenção das noções" (O Baependyano, 28 de dezembro de 1879, p.1).

O autor mineiro toma a palavra moderna como título de seu conceito de educação, acompanhando assim a lógica adotada pelo Baependyano que afirma a adoção de novos ideais em oposição às tradições vigentes até então. Uma das características que parece remeter ao caráter de novidade, no caso da educação, é a ênfase na noção de desenvolvimento humano, uma área de estudo emergente na época (GOUVEA e GERKEN, 2010). Diante disso, embora a instrução seja muito importante, o aspecto fundamental a ser considerado pelos educadores é o desenvolvimento em seus aspectos físico, racional e moral.

A racionalidade e a moralidade têm como base as faculdades da alma humana, aqui entendidas como forças. Assim como em outras definições de alma da época (ASSIS, 2009), Siqueira adota a ideia de 
força para exprimir o caráter ativo e progressivo do desenvolvimento humano, evidenciando a apropriação de conceitos da Física para a construção do campo psicológico. O paradigma de cientificidade era dado principalmente pelas ciências que descreviam as leis da natureza, por isso as ciências sobre o homem adotaram conceitos advindos da Biologia e da Física, principalmente referenciais newtonianos (VIDAL, 2006; GOUVEA e GERKEN, 2010):

\begin{abstract}
O triunfo da Física e principalmente a Biologia indicavam a propriedade do recurso aos conceitos e instrumentos teóricometodológicos das ciências físico-naturais para a abordagem desses problemas, sendo tais disciplinas tomadas como ordenadoras. A idéia de natureza, construída pela Física newtoniana, compunha um cenário de leis permanentes que se tornaram parâmetros da cientificidade. (GOUVEA e GERKEN, 2010, p. 19)
\end{abstract}

O discurso sobre o desenvolvimento global das forças físicas, racionais e morais do ser humano é fundamentado, no Baependyano, no Curso theorico e pratico de Pedagogia de Michel Charbonneau, segundo o qual para termos sucesso na educação é preciso conhecer a natureza do ser que se vai formar, compreender suas faculdades e a ordem a partir da qual elas se desenvolvem, além de estabelecer os diversos métodos e modos de cultivá-las (CHARBONNEAU, 1885, p. XIV), corroborando o interesse da época pela descrição das leis da natureza humana e pela sua evolução.

Michel Charbonneau (1817 - 1870) foi um educador francês dedicado à formação de professores, tendo sido ele mesmo Professor de Escola Normal de 1835 a 1847, Inspetor e, mais tarde, Diretor de Escolas Normais de diversas regiões da França. O manual, Curso theorico e pratico de Pedagogia (1862/1885), parece ter sido sua obra mais divulgada no Brasil. De acordo com Rapet (1885), o Curso de Charbonneau alcançou aceitação, em sua época, por ser visto como portador de dupla qualidade: sendo teórico ao expor os princípios da educação e ao instruir os professores, elevando seus espíritos e fazendo-os pensar; e também prático ao colocar os princípios disponíveis a todos com a habilidade própria de um educador fundamentado na experiência (RAPET, 1885).

Assim, Siqueira apropria-se das ideias de Charbonneau ao enfatizar a educação como cultivo e desenvolvimento dos germens e forças da alma. A adoção de um manual francês como referência principal para o discurso sobre educação, traz para José Miguel de Siqueira duas vantagens: a legitimação de seu ponto de vista por meio de um autor respeitado na época e o apelo às ideias francesas como característica de modernidade e ilustração. De fato, a literatura francesa tem forte presença no Brasil desde o século XVIII, sendo que, principalmente na segunda metade do XIX, começa a aparecer a divulgação também 
de autores norte-americanos. Já no início do século XX, a Professora Alexina de Magalhães Pinto preparou uma lista de bons livros sobre psicologia para leitura de educadores. Essa lista, realizada a partir dos programas de instrução pública de Minas Gerais, era composta apenas por obras francesas e norte-americanas e segundo a autora, não eram citados livros brasileiros, pois os títulos estrangeiros eram superiores aos nacionais (NEPOMUCENO e CAMPOS, 2004).

Todavia, Siqueira, apropriando-se do manual francês, acrescenta à definição original de Charbonneau, a ideia de que a educação tem como finalidade inspirar na criança e no jovem o amor ao bem. À essa educação, cujo objetivo consiste no cultivo das faculdades da alma a fim de direcioná-las para o bem, Siqueira chama de ensinamento ou educação cristã. Assim, o autor mineiro deixa evidente sua posição de adoção da doutrina católica como princípio norteador para a constituição dos saberes e práticas educacionais, afirmando que a religião seria a responsável por inúmeros fatores relacionados ao desenvolvimento do ser humano e da sociedade:

\begin{abstract}
desenvolveu seus instinctos sociaes, e suas faculdades intelectuais e Moraes; pôz valente freio nas paixões reprehensiveis; moderou seus prazeres; tranqüilizou os ânimos mostrando, que há necessidade de uma Providencia viva, presente, que vela incessante sobre o homem e sobre a humanidade em pezo; Providencia que regula e rege tanto o mundo physico, como o moral. (O Baependyano, 23 de abril de 1879, p. 1)
\end{abstract}

Emerge, portanto, um aspecto bastante comum no panorama brasileiro que é a forte presença das ideias católicas como um dos referenciais que ordenavam as apropriações de teorias estrangeiras, resultando numa síntese original que buscava uma conciliação entre os ideais vistos como novos e modernos e a tradição cultural presente no país. É comum, por exemplo, nesses jogos de apropriação, que autores brasileiros adeptos de teorias francesas recorram à tradição católica como forma de deixar claro que, apesar de sua adesão às modernas ideias filosóficas, científicas e educacionais, suas propostas se distanciavam de perspectivas como o materialismo e o deísmo (ASSIS, 2004; ASSIS, 2011).

Nessa síntese entre tradicional e moderno, a educação como cultura das faculdades da alma deveria desenvolver as prerrogativas para o exercício da virtude, sendo esta última entendida como a força para vencer a si mesmo a fim de praticar o bem:

Tem o homem um só motor e um só principio, disse alguém, é o desejo e o pensamento do bem, com todas as certezas, ou se vos apraz melhor, com todas as fraquezas, com todos os erros de sua natureza fraca, mas também com esses generozos esforços, com essa constancia firme, com esses 
sublimes instinctos e essa consciência serena e pura, que fizeram, em todos os tempos e logares, os homens de bem, os heroes, os virtuosos, os sanctos, numa palavra. (O Baependyano, 09 de novembro de 1879, p. 1)

Partindo da tópica aristotélica, presente nas propostas educacionais já vigentes, segundo a qual a virtude situa-se no justo-meio entre os extremos, o cultivo da virtude consistia em habituar a alma humana a controlar-se com constância, esforço e serenidade de consciência, opondo-se assim aos vícios e paixões e vencendo a natural fragilidade da alma humana quando fica diante de um forte desejo. Assim, a consciência é a instância capaz de opor-se e, consequentemente, controlar os aspectos passionais presentes na alma humana.

A dinâmica da virtude, ou seja, da vitória da consciência sobre si mesmo, é importante para que se possa aderir livremente ao desejo e ao pensamento do bem, contribuindo assim para a construção da nação, como fica claro nessa citação: "no meio da prodigalidade e da avareza, está a economia, que apparelha o bem do indivíduo, das famílias e dos Estados." ( 0 Baependyano, 09 de novembro de 1879, p. 1). Sendo assim, o cultivo do hábito da virtude não serve apenas como incremento individual, mas é necessário para a construção do país, já que os homens são os órgãos da sociedade. Um órgão que funciona mal ou enfermo pode trazer problemas para todo o organismo. Enquanto a medicina deve zelar pelas doenças do corpo, a educação é a responsável pela profilaxia das doenças sociais. E, para que tal prevenção possa, de fato, ocorrer, é necessário o auxílio dos saberes sobre as faculdades da alma humana e o funcionamento de suas leis.

Nessa perspectiva, para vencer os excessos que, facilmente se transformam em enfermidades, bem como se opuser à violência passional, é preciso que todas as sensações e paixões estejam sob o domínio de uma razão reta e justa. A razão, por sua vez, é uma das faculdades da inteligência. Assim, vemos que para que a ação virtuosa aconteça é preciso o exercício conjunto de todas as faculdades da alma de modo que elas estejam voltadas em uníssono para o bem, aqui entendido como a construção da própria pessoa e da sociedade.

De acordo com Charbonneau (1862/1885) e, consequentemente, com Siqueira, três forças formam a natureza humana: as forças físicas, racionais e morais. Sendo assim, como era ideia corrente na época, as faculdades da alma são também três: a inteligência ou entendimento, a sensibilidade e a vontade. A inteligência, responsável por buscar e conhecer a verdade, é formada por faculdades como atenção, julgamento, razão, memória, imaginação. A sensibilidade é a faculdade de gozar ou sofrer, ou seja, sentir de modo prazeroso ou doloroso os eventos que acometem o corpo e 
também a alma. A vontade, por sua vez, é caracterizada pela escolha, ou seja, a possibilidade de decisão livre. Embora formada por três aspectos, a alma é única, sendo as faculdades entendidas como forças da alma que funcionam em uníssono. A inteligência compõe a força racional, enquanto a sensibilidade e a vontade reunidas formam o domínio moral. Esta forma de organizar os saberes sobre as faculdades da alma pode sofrer modificações de acordo com a corrente teórica seguida pelos autores que os sistematizam. Particularmente em Minas Gerais, na metade do século XIX houve a divulgação de filosofias das faculdades da alma fundamentada nas ideias de Pierre Laromiguière, Victor Cousin, J osep Marie Degérando, assim como a circulação de saberes sobre as faculdades da alma elaborados por grupos católicos (Assis, 2009). Siqueira, sem dúvida, conhece bem tal tradição, pois ao tratar das faculdades da alma, assim como de outros temas, cita Degérando e Cousin. Também utiliza dos ideais católicos como veremos a seguir.

$\mathrm{Na}$ época, podia-se conceber que o ser humano recebe as forças da alma em potência, ou seja, os germens, quando recebe a vida. Assim, as faculdades são intrínsecas à natureza humana, formando uma espécie de estrutura representada pelas relações entre forças específicas que colocam a alma em ação, possibilitando a dinâmica e o desenvolvimento do psiquismo humano, bem como de todo o organismo. Embora essa estrutura seja inerente à natureza humana, o desenvolvimento das faculdades pode sofrer modificações de acordo com o clima de um lugar, o governo e a educação adotada, as opiniões, ou seja, de acordo com a ação de diversas causas contextuais. Nesse ponto, apresenta-se a discussão sobre a cultura das faculdades ou forças da alma, ou seja, sobre o desenvolvimento ocorrido a partir da relação da pessoa com o seu ambiente e do exercício das práticas sociais sobre o espírito humano.

\section{A cultura do homem polido e civilizado}

A palavra cultura, no jornal O Baependyano, sempre aparece atrelada aos conceitos de desenvolvimento e educação moral:

Sem esta cultura e disinvolvimento, sem esta educação não pode dar a sua família prudentes conselhos, nem prestar a seus similhantes aquelles serviços, que teem elles direito d'esperar d'elle, nem mesmo offerecer verdadeira homenagem a seu Creador, que cumpre ser adorado em espírito e verdade, segundo o espírito do Evangelho. ( $O$ Baependyano, 16/nov/1879, no 119, p. 1)

No discurso de Siqueira, existem duas posições complementares a respeito da cultura das faculdades da alma e de suas relações com a 
educação: o argumento de que a maneira de educar é diferente em lugares diversos, dependendo dos grupos sociais e do ambiente aos quais pertencem; e a ideia, bastante presente no século $X I X$, de que por meio da educação é possível a realização de uma construção específica da pessoa e da sociedade. Essa última atitude, de acordo com Massimi (2006), resulta de uma posição, presente no século XIX, que subordina a cultura às ciências e saberes positivos, já que cabe à ciência explicar, controlar e manipular a realidade e a natureza. Desse modo, a escolha por uma ou outra forma de cultivo do espírito humano depende de que tipo de nação se deseja construir e dos saberes ou ciências capazes de proporcionar tais diretrizes, ficando a palavra cultivar entendida como civilizar:

O filósofo austro-italiano R. Guardini (1995) aponta que o conceito de cultura na Idade Moderna foi identificado com a elaboração e a realização de projetos civilizatórios - produtos de determinados modos de ação e fazeres humanos implicados na construção de sua própria existência. (MASSIMI, 2006, p. 181)

Assim, a cultura, como discute Massimi (2006, p. 182), "é algo que o homem faz e também o instrumento que usa para fazer-se e fazer o outro". Essa concepção é a que está presente no periódico mineiro, bastante afinada com os projetos civilizatórios presentes no século XIX, no Brasil. Siqueira define cultura apropriando-se de uma tradição bem antiga, ou seja, a da imagem de cultivo da terra. $O$ significado de cultura está associado à "colere", palavra latina que significa cuidar, criar e preservar. Originalmente relacionada às atividades agrícolas, a palavra começou também a ser utilizada para o cuidado e hábito da alma (MASSIMI, 2006). Daí que seja possível cultivar a alma humana e suas faculdades.

Nas páginas da Seç̧ão Scientifica ou Pedagogia, o homem bem cultivado torna-se um cidadão polido, instruído, laborioso e honesto que representa em si a dignidade e a virtude e colabora para a construção da nação. Isso acontece porque, de acordo com José Miguel de Siqueira, as impressões e traços desenvolvidos na infância decidem o caráter e o procedimento moral do homem quando adulto. Siqueira utiliza-se da noção de tabula rasa, estabelecendo relações entre suas ideias educacionais e de desenvolvimento e explicações sobre o cérebro humano:

Ora, se pode o cérebro da criança comparar-se, como já ficou indicado, como um livro em branco, cujas folhas limpas esperam, que nellas se escreva, conceberemos quam essencial seja, que mão mestra, mão firme e segura, mão prudente e sábia estampe esse livro vivo em characteres indeléveis, a virtude. ( $O$ Baependyano,30 de novembro de 1879, p. 1) 
A mão mestra pertence àquele que ensina por meio de exemplos e de conselhos, ou seja, o homem civilizado capaz de cultivar as crianças e jovens, ensinando-os, através de sua própria ação, a controlar as paixões humanas para que a dignidade humana e os deveres sociais sejam respeitados. A educação, nessa perspectiva, como já vimos anteriormente, é a responsável por habituar a alma a domar o corpo e vencer os desejos ilícitos a fim de seguir a razão reta e esclarecida unida ao sentimento moral e religioso. A essa unidade entre razão reta e sentimento moral, Siqueira dá o nome de consciência.

Desse modo, a natureza primitiva do ser humano e das sociedades devem ser desenvolvidas e civilizadas, por meio da cultura, a fim de dar lugar a uma nova natureza regida pelo governo da consciência. $O$ desenvolvimento adequado, por sua vez, depende das práticas estabelecidas para o cultivo da pessoa.

Como já vimos, a trajetória de desenvolvimento do ser humano é, por um lado, determinado pela educação que recebe, e, por outro lado, depende também de sua natureza, mostrando que, para Siqueira, o desenvolvimento do ser humano obedece a uma delicada relação entre fatores ambientais e natureza humana.

De acordo com Gouvêa e Gerken (2010), no século XIX impõe-se uma visão segundo a qual a natureza está em constante movimento e transformação, vindo à tona os conceitos de desenvolvimento e evolução (GOUVEA e GERKEN, 2010) e de suas faculdades. De fato, essa visão está presente no Baependyano, assim como em outros jornais da época. O Jornal de Minas (1890), por exemplo, publica um texto intitulado A evolução da literatura, em que se discute a evolução da mentalidade do povo brasileiro.

A diversidade entre os seres humanos se explica pela presença de fatores como clima, lugares, tempo histórico, tipos de educação, bem como de formas de impressão e presença de objetos, como demonstra a Carta de Clemente XIV citada por Siqueira:

Diz Clemente $14^{\circ}$, numa de suas elegantes chartas, tractando como philosopho do homem em geral, - que a maneira de educar os homens, o clima em que nascem, as impressões que recebem, e os objectos que o circundam, formam outros tantos moldes, em que tomam diversas formas.

Assim, o homem que nasceu nas Índias, não é o homem da Europa; o homem doctrinado por Artistóteles, não é o homem formado por Newton.

A essência é a mesma, mas as cores são differentes, que é inteiramente outro o modo de sentir, de perceber e de pensar. (O Baependyano, 28 de dezembro de 1879, $n^{\circ} 125$, p. 1) 
Aspectos ligados à circunstâncias específicas, como por exemplo, o lugar ou a época em que se nasce podem determinar maneiras de pensar, sentir e perceber. A natureza humana é a mesma, pois sensibilidade, inteligência e vontade são aspectos intrínsecos à alma humana. Entretanto, as formas pelas quais essas faculdades se relacionam com os seus objetos podem se diferenciar. Nesse sentido, a metáfora do cultivo das plantas para o desenvolvimento do ser humano é bastante pertinente ao pensamento da época, já que é possível moldar uma planta, mas é impossível modificar, naturalmente, as características de sua espécie. Ou seja, para Siqueira, é possível construir um determinado ser humano por meio da cultura, mas o tipo de cultura deverá, necessariamente, se conformar às propriedades inerentes à alma humana.

Ao lado da organização da alma humana comum a todas as pessoas, para Siqueira, o ser humano também é dotado de aspectos inatos que conferem o caráter de universalidade entre os seres humanos:

Da qualidade do terreno depende o viço ou enfezamento da
vegetação; eis a fiel imagem da educação.
Não que esta seja absolutamente tudo, e a natureza nada,
segundo já ficou ponderado em outro logar, como querem
Hobbes, Mandeville, Helvécio, D'Holbbach e outros
materialistas deste tomo, não, não, e ainda não; há
liniammentos primitivos, há germens, há propensões, há
pressentimentos, há mesmo certas noções innatas, que peze
ao sábio Locke e a seus sectários; há numa palavra,
organizações aptas e inaptas, como há terrenos fecundos e
istereis. (O Baependyano, 30 de novembro de 1879, p. 1)

Durante o século XIX, circulou, no Brasil e particularmente em Minas Gerais por meio do movimento liderado pelo Bispado de Mariana, a ideia de que a natureza humana e a organização da sociedade possuem relações naturais e necessárias com Deus, que devem ser desenvolvidas e não violadas. Siqueira toma o inatismo a fim de colocar-se ao lado das ideias católicas que, no estado, afirmava a necessidade de se levar em consideração as relações intrínsecas entre Deus e o homem. Assim, o autor mineiro contrapõe-se a John Locke e também ao materialismo associado a filósofos como o Barão de Holbbach e Helvecio, autores bastante divulgados em Minas Gerais. Nesse sentido, para o autor brasileiro, existem ligações, propensões e ideias inatas ao ser humano. Sendo o homem e o mundo um ato do Criador, as relações entre Deus e o homem, impressas na alma humana e na ordem da sociedade, não devem ser violadas e por isso a dignidade humana deve ser respeitada. A dignidade humana é definida como retidão e pureza de costumes. Nesse sentido, o aspecto mais importante da cultura educacional é a educação moral e religiosa. 
Partindo da tradição cristã, José Miguel de Siqueira considera como virtudes a caridade, a esperança, a fé, a justiça, a temperança, a prudência e a fortaleza. As virtudes assim definidas podem ser encontradas em diversas obras da tradição cristã, como nas epístolas de São Paulo citadas na Secção:

Que diz da caridade o homem de mais profundo juízo dos antigos séculos, o sempre grande Paulo? Ella é paciente, é benigna; não é invejosa, não obra temerária, nem precipitadamente não se ensoberbece, não busca os seus próprios interesses, não se irrita, não suspeita mal, não folga com a injustiça, mas folga com a verdade; tudo tolera, tudo crê, tudo espera, tudo soffre. (O Baependyano, 09 de março de 1879, p. 1)

Ao lado dessas, a polidez é apontada como virtude social e principal característica do homem civil e bom cristão. Na época, a polidez, tema largamente tratado pelas obras literárias francesas, era vista como expressão do refinamento dos costumes e símbolo de uma sociedade civilizada, pois representava a capacidade de autogoverno por meio do controle e regulação dos aspectos passionais da alma humana (GOUVEA e GERKEN, 2010). Daí a importância do cultivo das virtudes.

Assim escreve José Miguel de Siqueira a respeito da polidez:

\begin{abstract}
Ella faz o homem parecer no exterior o que deveria ser no interior; cifra-se ella nessa attenção em fazermos que, por nossas acções e palavras, fiquem os demais contentes comnosco.

Pode - se dizer que ella é a religião da cortezania, e é em relação aos homens entre si, o que é o culto em relação a Deus - um testimunho externo e sensível dos sentimentos internos e occultos. [...] Ella é a devoção dos homens uns para com os outros, revelação por signaes de bemquerença, de respeito, de affeição. Observaremos por ultimo, que ella se exerce mais frequentemente nas altas e cultas reuniões d'ambos os sexos. (O Baependyano, 23 de fevereiro de 1879, p. 1)
\end{abstract}

De acordo com Gouvêa e Gerken (2010), civilizar tinha o sentido de corrigir e polir os costumes de um povo a fim de produzir uma moralidade capaz de traduzir-se em boa obras. De fato, esse espírito está presente nos escritos de Siqueira e em consonância com os ideais do Baependyano que buscava ilustrar a população, valorizando o trabalho como modo de construir a sociedade civil. Nesse projeto, Siqueira defende que o país não precisa de homens letrados, mas de lavradores e divide a instrução em dos tipos: o ensino das primeiras letras que deveria ser dado àqueles que se dedicassem aos trabalhos manuais e os altos estudos para aqueles que fizessem parte das 
classes mais favorecidas. Daí a ideia de que a cultura da inteligência e da moralidade deveria ser a parte mais importante da educação, pois era importante educar todos os homens para serem cidadãos honestos, úteis, polidos e, consequentemente bons trabalhadores, enquanto a instrução mais acurada seria realizada apenas para parte da população, isto é, aquela que carregava os signos da civilidade.

De fato, como afirmam Gouvêa e Gerken (2010), a definição de polidez carregava uma perspectiva eurocêntrica que "tomava os costumes e os padrões culturais europeus como sinônimos de costumes civilizados" (GOUVEA e GERKEN, 2010, p. 26):

\footnotetext{
Nós precisamos, principalmente de quem trabalhe, e não de cardumes de utopistas, [...] e nem tão pouco de metaphysicos nebulosos; necessitamos de homens positivos, práticos, que apliquem as sciencias às artes, officios e industrias, como fazem os inglezes e os norte-americanos; imitemos a estes dois povos e iremos bem. (O Baependyano, 06/04/1879, n. 91, p. 1)
}

A pessoa polida e civilizada não se dava aos excessos, pois afetações extravagantes não convinham ao homem sociável ( $O$ Baependyano, 23 de fevereiro de 1879, p. 1). A fim de evitar os excessos e garantir o bom desenvolvimento da pessoa polida e da sociedade civilizada, tornava-se necessário o conhecimento das leis que ordenavam as faculdades da alma de modo a cultivá-las adequadamente tanto no aspecto racional quanto no moral. No bojo desse projeto civilizatório, a psicologia, como estudo das faculdades da alma humana, emerge como saber fundamental para o campo da educação.

\section{Considerações finais}

Enfim, no Baependyano encontramos a ideia de que a instrução e a cultura das faculdades da alma humana são aspectos indissociáveis, pois a eficácia da educação depende de sua capacidade de cultivar a alma nos aspectos cognitivos e morais, orientando o ser humano para o caminho do bem. Esse direcionamento das faculdades é necessário, já que a virtude é considerada a força que se opõe à violência das paixões e dos desejos ilícitos nos ajudando a vencermos a nós mesmos para praticarmos o bem. Do mesmo modo, para que a educação seja eficaz em sua tarefa, é preciso saber de que modo as faculdades da alma humana se organizam a fim de que possam ser bem orientadas.

Dialogando com sua época, vemos que este periódico mineiro entende a pedagogia como meio soberano para a formação de homens verdadeiramente polidos, promovendo assim a construção da 
sociedade e da pátria. De fato, durante o século XIX, a imprensa periódica toma para si os propósitos de civilizar a população e aprimorar a sociedade tendo como principal instrumento para tal empreitada a construção e a divulgação de um ideário educacional moderno (Faria Filho, Nascimento, Inácio e Jinzenji, 2008).

Ao nos centrarmos nas formas de apropriação, observamos que os compêndios e as ideias de diversos autores são utilizados de acordo com as finalidades do grupo que editava um impresso. Também no caso do Baependyano isso acontece, já que Siqueira apropria-se de diversos saberes a fim de elaborar suas ideias. Esses saberes estão fortemente relacionados à circulação de ideias por meio da cultura impressa no contexto mineiro e brasileiro do século XIX. Como já foi apontado no decorrer do texto, Siqueira dialoga com a forte tradição filosófica católica presente em Minas Gerais, com os temas educacionais presentes em outros jornais e também com os manuais e autores tidos como novos e modernos para a sua época, como Michel Charbonneau e Friedrich Froebel. Siqueira faz eco às críticas e às teorias divulgadas pela Igreja Católica ao definir seu conceito de cultura; conceito por meio do qual afirma as relações intrínsecas entre Deus e o ser humano, a existência de uma natureza humana criada e formada por forças específicas mas que pode sofrer modificações dependendo da maneira como é desenvolvida e do contexto no qual está inserida. Assim, aquilo que aparece no jornal não é uma simples transcrição dos manuais, dos autores considerados pela época ou da tradição católica em linguagem mais fácil e vulgarizada dos saberes, mas é uma outra coisa, ou seja, um saber próprio que se assemelha e se diferencia do conteúdo dos compêndios e autores adotados resultando em sínteses originais. Como bem expressou Moscovici (1978), ao tratar da representação social, existe um nível do senso comum em que ideias, imagens, práticas etc., da ciência são transformadas em imagens, ideias e práticas do senso comum, sem que haja uma diferença de valor entre uma e outra. Esses aspectos fazem com que os gêneros literários jornais, revistas e periódicos, não propriamente entendidos como científicos, possam se constituir, ao mesmo tempo, em interessantes objetos de pesquisa e também em fontes expressivas para os estudos em História da Psicologia, já que são capazes de expressar aspectos dos ideários produzidos por autores brasileiros em suas apropriações dos saberes disponíveis em seu contexto.

\section{Referências}

ARAÚjO, M. M. Uma história de precursores e ativistas. Revista do Arquivo Público mineiro, Belo Horizonte, n. 1, p. 20-23, janeirojulho 2008. 
ASSIS, R. M. Psicologia, educação e reforma dos costumes: lições da Selecta Catholica (1846 - 1847). 2004. Tese (Doutorado em Educação) - Programa de Pós-graduação da Faculdade de Educação, Universidade Federal de Minas Gerais, Belo Horizonte.

ASSIS, R. M. A importância da educação e da tradição: lições do jornal religioso Selecta Catholica (1846 - 1847) sobre o cultivo das faculdades da alma e do espírito humano. Memorandum, Belo Horizonte, n. 8, p. 106-115, 2005.

ASSIS, R. M. Psicologia filosófica no século XIX. Psicologia: reflexão e crítica, Porto Alegre, n. 1, p. 304-311, 2009.

CASTILHO, F. F. A.. Entre a locomotiva e o fiel da balança: transição da mão-de-obra no Sul de Minas (1870-1918). 2009. Dissertação (Mestrado), Universidade Federal de Juiz de Fora, Juiz de Fora.

CHARBONNEAU, M. Cours théorique et pratique de pédagogie Paris: Librairie Ch. Delagrave, 1885.

FARIA FILHO, L. M.; JINZENJI, M. Y.; NASCIMENTO, C. V.; INÁCIO, M. S. Educar para civilizar. Revista do Arquivo Público Mineiro, Belo Horizonte, v. 44, n. 1, p. 72-87, janeiro-junho 2008.

GOUVÊA, M. C. S.; GERKEN, C. H. S. Desenvolvimento humano: história, conceito e polêmicas. São Paulo: Cortez, 2010.

LUSTOSA, I. O nascimento da imprensa brasileira Rio de Janeiro: J orge Zahar Editora, 2003.

LUSTOSA, I. Historiadora relata sua rica trajetória de pesquisa em periódicos brasileiros desde o surgimento da imprensa em nosso país. Revista do arquivo Público mineiro, Belo Horizonte, v. 44, n. 1, p. 8-19, janeiro-junho 2008.

MASSIMI, M. Psicologia e cultura na perspectiva histórica. Temas em psicologia, Ribeirão Preto, v. 14, n. 2, p. 177-187, 2006.

NEPOMUCENO, D. M.; CAMPOS, R. H. F. Fontes para a difusão das idéias psicológicas em Minas Gerais entre 1830 e 1930. Memorandum. Belo Horizonte, n. 6, p. 114-123, 2004.

MOSCOVICl, S. A Representação Social da Psicanálise. Rio de Janeiro: Zahar, 1978. p. 41- 81.

PALLARES-BURKE, M. L. The Spectator: o teatro das luzes - diálogo e imprensa no século XVIII. São Paulo: Hucitec, 1995.

RAPET, J. J. Introduction: utilité et but dês études pédagogiques. In: CHARBONNEAU, M. Cours théorique et pratique de pádagogie. Paris: Librairie Ch. Delagrave, 1885.

RODRIGUES, J. C. I déias filosóficas e políticas em Minas Gerais no século XI X Belo Horizonte: I tatiaia; São Paulo: EDUSP, 1986.

VIDAL, F. Lês sciences de l’âme: XVI - XVIII siècle. Paris: Honoré Champion, 2006. 
Raquel Martins de Assis, Juliana de Souza Martins

Cultura e desenvolvimento humano

\section{Endereço para correspondência}

\section{Raquel Martins de Assis}

R. dos Maçaricos 45/casa 05, Vila Clóris - Belo Horizonte/MG.

Endereço eletrônico: raamart@yahoo.com.br

J uliana de Souza Martins

R. Euclides Andrade 235, Santo André - Belo Horizonte/MG.

Endereço eletrônico: julianaszm@yahoo.com.br

Recebido em: 01/12/2011

Reformulado em: 18/05/2012

Aceito para publicação em: 29/05/2012

Acompanhamento do processo editorial: Ana Maria Jacó Vilela 